\section{Military Technical College Kobry El-Kobbah, Cairo, Egypt}

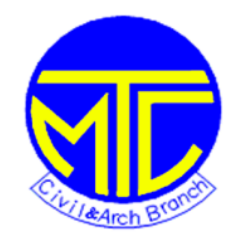

\section{$8^{\text {th }}$ International Conference on Civil and Architecture Engineering ICCAE-8-2010}

\title{
Seismic responses of shear wall utilizing three-dimensional dynamic interaction of super-structure with multi-basement and side soil
}

\author{
By \\ Mustafa Abdulla Hussein*
}

\section{Abstract:}

The common structural design practices usually assume the super-structure to be fixed at the ground level ignoring the presence of either single or multiple basements. This paper is concerned with three-dimensional dynamic interaction analysis of super-structure with basement(s) surrounded by dry side soil and resting on bed rock. More precisely, it investigates the seismic responses of above- and under-ground portions of shear wall as a part of building system. In addition, this full interaction analysis is performed for assessing non-interaction analysis of super-structure with traditional fixed base at ground level. The studied variables include the effect of number of basements $(1,2,3,5)$ and density states of side soil (loose and very dense). The building is idealized by shell and frame elements; while the side soil is idealized by 8 -noded brick elements and repeatable side boundaries to allow for the induced seismic waves to dissipate from the side boundaries without being reflected back into the soil domain. Further objective is to assess a proposed partial interaction simulation without accounting for the side soil modeling against the full interaction one to reduce the analysis complexity and computer needed capacity and run-time.

This study is carried out using linear elastic transient dynamic three-dimensional finite element module of ADINA program under the effect of Northridge-1994-USA Earthquake applied at the bottom boundary (bed rock surface). The results showed minor effect of side soil conditions and its absence on seismic responses of the above- and under-ground portions of shear wall in buildings of (3-basemnts or less). In addition, the highest shear force value in the whole shear wall is developed at first basement level. Further, the fixity assumption of building at ground level develops conservative seismic responses of the shear wall.

\section{Keywords:}

3-D dynamic soil-structure interaction, Seismic responses, Shear wall, Basement(s), Side soil state, finite element.

* Assoc. Prof., Structural Engineering Dept., Faculty of Eng., Zagazig University, Egypt. E-mail: mhowili1@ hotmail.com. 


\section{Introduction:}

Traditionally, the super-structure is designed assuming fixed supports at ground level without accounting for the effect of under-ground stories. In fact, the actual level of fixity of building dictates the natural vibration period of the building and hence the values of related seismic base shear. In addition, increasing the basement rigidity minimizes the seismic relative displacement between basement floors; and hence the fixity assumption of super-structure at ground level may be achieved. Actually, the basement rigidity is developed by its peripheral walls parallel and perpendicular to the ground motion. These basement walls resist the seismic forces by acting as shear wall of large in-plane bending stiffness and vertical slabs resting on side soil, respectively, as resulted in this paper.

Typical sources of uncertainty in earthquake engineering are those in ground motion and dynamic structural properties. Major uncertain properties in the structure are mass, viscous damping, strength, stiffness, structural geometry and soil-structure interface. Unlike uncertainty in structural properties, the ground motion is more difficult to characterize [1]. In fact, under-ground structures are constrained by the side soil or rock and cannot move independently; so they are affected by the deformation of the surrounding soil in addition to the inertial forces exerted from the super-structure [2]. Therefore, it is recognized in some codes that the effects of dynamic soil-structure interaction shall be taken into account in case of massive or deep seated foundations [3].

Most of commercial multi-story structures may have basement(s), where the retaining walls experience additional earth pressure both from the action of the surrounding soil and the structural dynamic movement. It is a three-dimensional (3D) problem and really requires a 3D dynamic analysis [4]. Actually, the basement may change the seismic inputs to the building from those predicted at the free field, but there is no consensus on the best procedures for the selection and scaling of earthquake records (time histories) [5]. This will affect the lateral displacement (story drift) and vibration period of the building, which is an important issue for performance based design.

Most building codes treat low and medium rise regular buildings with multi-basement similar to the recommendations used for surface foundation buildings. In general, buildings with multiple basements are designed by separating the super-structure and analyzing it as a fixed base structure founded on the ground surface. While the substructure is designed for the seismic base shear and moment demand resulting from super-structure in addition to the seismic earth pressure acting on the basement walls due to oscillating mass of the side soils [5,6].

Soil-structure interaction effects are significant for buildings resting on flexible ground surface with no under-ground stories, and gradually decrease with the 
increase of the number of under-ground stories. However, it is important to incorporate the under-ground floors, basement walls, foundation soil and side soil explicitly in the mathematical model of the structure to be able to assess the effect of the under-ground part of the building adequately on its seismic performance. This concept indicates that the largest seismic shear force is developed in the first basement and gradually decreases in the lower basements for the dynamic interaction of framed structure with basements [6].

In literature, the lateral stiffness of high-rise building structure may be significantly overestimated resulting in larger lateral displacements and shorter natural periods of vibration if the basement is ignored in the analytical model. Especially in case of building with shear walls, the effect of basement on the seismic responses turned out to be more significant [7]. Further, direct foundation-soil contact (i.e. without basement) needs large size to support shear wall building system because of large seismic bending moment; while box basement structures are alternative solutions that provides horizontal elastic supports to the shear wall at the ground floor and raft slab horizontal diaphragms [8].

Indeed a suitably proportioned shear walls are very effective means of achieving stiffness against loads together with good ductility demand [9]. This concept is adopted in this paper through conducting trial dynamic analyses to select crosssectional areas of the shear walls that develop suitable inertial forces and roof drift.

The shear walls are generally modeled as shell elements with in-plane and out of plane stiffness. The standard wide column analogy using 3D beam elements offers a simpler alternative for appropriate representation of shear wall and can be used for multi-bay multi-story structure where the results can be directly used for design [10].

\section{Objectives:}

This paper investigates the dynamic behavior of above- and under- ground portions of shear wall in building utilizing three-dimensional seismic interaction of superstructure with the basement floors and dry side soil; while this interaction system resting on bed rock. Specifically, the studied seismic responses of the shear wall are roof drift, inertial shear force in earthquake direction $(\mathrm{X})$ and bending moment around the perpendicular Y-axis. These straining actions are investigated for points at distances of $0.25 \mathrm{~m}$ above the floor levels of the shear wall to avoid modeling problem.

The investigated variables in this dynamic study are presented in table 1 . These variables comprising number of under-ground basements 1,2, 3 and 5, two states of side soil densities (loose and very dense) surrounding the basement(s), ignoring the 
whole under-ground part of the system by assuming the building of fixed ground base and ignoring the side soil modeling only. It should be noted that the case of 5basements is studied to check the validity of results and under-ground extension of building at expensive land of limited height as well.

In summary, finite element transient dynamic analyses are conducted and time history charts are presented to fulfill the following categorized objectives:

A. Seismic responses of above-ground portion of the shear wall in super-structure with basement(s) and dry side soil (full interaction systems). This item is investigated as follows:

1. Assessment of dynamic analysis of non-interaction system of super-structure with fixed base at ground level.

2. Effect of number of basements.

3. Effect of side soil states.

B. Seismic responses of under-ground portion of shear wall at different number of basements and side soil states.

C. Assessment of seismic responses of above-and under-ground portions of shear wall in partial interaction building simulation, which ignoring the side soil modeling. The purpose of such simulation is to reduce the complexity of the full interaction problem that consuming high computer needed capacity and run-time. In addition, this item investigates the effect of side soil on the basement rigidity formulation.

\section{Building description and modeling:}

The studied models presented in table 1, and shown in figures 1, 2a, 2b, 2c, 2d and 3 are concrete shear-wall resisting buildings of 10 above-ground stories, typical 4meters story height and super-structural plan dimension of $18 \times 20$ meters. The buildings have under-ground basement(s) of plan dimension enlarged by $4 \mathrm{~m}$ around the super-structural plan. In addition, the above- and under-ground floors are flat slabs of $0.25 \mathrm{~m}$ thickness without openings, and directly supported by the shear-walls and columns. Further, the cross-sectional areas of these ends are kept constant allover the height; since the seismic performance of the buildings rather than its seismic design is the objective of this paper. Furthermore, the building is founded on raft foundation of $1.0 \mathrm{~m}$ thickness that considered as fixed plan but released in X-direction to apply the earthquake excitation. Moreover, building uplifting and hence the probability of rocking phenomena [11] is not considered in this study.

Actually, the cross-sectional areas of the shear-walls are chosen to develop an acceptable seismic inertial forces and lateral roof drift as resulted from trail dynamic 
analyses that conducted on proposed cross-sectional areas for the shear walls. However, shear walls of label (A), as shown in figure 2a, are chosen of dimensions $0.4 \mathrm{~m} \times 2.0 \mathrm{~m}$ to resist ground motion in X-direction. In addition, other vertical supports labeled as (B) and (C) are chosen of cross-sectional dimensions of $0.4 \times 1.0 \mathrm{~m}$ and $0.65 \times 0.65 \mathrm{~m}$, respectively. Further, the basement retaining walls have thickness of $0.3 \mathrm{~m}$ and supporting the basement slabs as well.

The side soil is represented by elastic half space of $50 \mathrm{~m}$ extension on both sides of the basement in X-direction, as shown in figures $1,2 \mathrm{a}$, and $2 \mathrm{~b}$. This soil media is modeled by 8-noded brick elements of assumed fully bonded nodes with the basement retaining walls and bed rock. In addition, repeatable side boundaries [12] are used in modeling the soil boundaries to prevent seismic wave reflection inside the soil media. This boundary condition is fulfilled by connecting rigid links between the corresponding finite element nodes of the two end sides of the soil media that perpendicular to the earthquake direction. Further, the side soil is considered as dry sand in loose and very dense states. These two cases of side soil are simply represented as linear elastic material having (elastic modulus, poison's ratio and density) properties of $\left(2.5 \mathrm{Kg} / \mathrm{m}^{2}, 0.25\right.$ and $\left.1600 \mathrm{Kg} / \mathrm{m}^{3}\right)$ and $\left(20 \mathrm{Kg} / \mathrm{m}^{2}, 0.4\right.$ and $1900 \mathrm{Kg} / \mathrm{m}^{3}$ ), respectively.

Moreover, the shear walls and columns are modeled by frame elements; while the floor slabs and basement retaining walls are modeled by shell elements.

It should be noted that the in hand study is concerned with investigating the shear wall labeled (A) in figure 2a. Therefore, all shear walls and columns are finely meshed by line segments of $0.25 \mathrm{~m}$ length. While the shell and 8 -noded brick elements are roughly meshed as $2.0 \times 2.0 \mathrm{~m}$ and $2.0 \times 2.0 \times 2.0 \mathrm{~m}$, respectively. Actually, preliminary dynamic analysis runs show very close seismic response results of the concerned shear wall (A) using shell elements of sizes $(2.0 \times 2.0 \mathrm{~m})$ and $(0.25 \times 0.25 \mathrm{~m})$ for the partial interaction system of 5-basements. Hence, it is decided to use coarse meshing for slabs, basement walls, and side soil which are suitable for investigating the shear wall and saving a lot of computer needed capacity and run-time.

\section{Dynamic time history analysis and discussion of results:}

The in hand interaction study is conducted using transient dynamic three-dimensional finite element module of ADINA computer program [13], under the time history effect of Northridge-1994-USA-Earthquake displacement records in X-direction at bottom of both basement and its surrounding side soil. The acceleration-time records of this earthquake in $\mathrm{X}$-direction are presented in figure 3a showing maximum acceleration of $18.5 \mathrm{~m} / \mathrm{sec}^{2}$. In addition, the masses considered for the dynamic 
Proceedings of the $\boldsymbol{8}^{\text {th }}$ ICCAE-8 Conference, 25-27 May, $2010 \quad$ GE 5

models are the element own weights of super-structure, basements and side soil. Further, all materials used in this analysis are assumed to be of linear elastic behavior. In fact, the natural frequencies and modal damping ratios of the noninteraction system of super-structure with fixed ground base may be significantly different from that of full interaction system utilizing the basement(s) and side soil [14]. However, in the elastic dynamic analysis of most structures and soils subjected to earthquake motions it is very common to use 5\% Rayleigh damping for all modes [15]. This ratio is fulfilled herein by applying multiplier factors to the stiffness and mass matrices as recommended by the software manual.

In fact, huge amount of results are obtained from this parametric study and hence only sample results are introduced and arranged here to cover all the studied models. In addition, suitable constant limit values for the chart ordinates are chosen to accommodate most ranges of the plotted results for comparison purpose. These limit values are plotted as two thin horizontal lines on other charts of higher range of results.

\subsection{Seismic roof drift, shear force and bending moment at ground level for} shear wall in building of basement(s) with dry side soil (full interaction system)

\subsubsection{Assessment of analyzing the building with fixed ground base (non-interaction system)}

Sample results are presented for a chosen nominal model of 3-basements in figure 4. This figure shows maximum absolute values of roof drift, shear force and bending moment at ground level of $(0.492 \mathrm{~m}, 329$ tons and $1869 \mathrm{~m} . t o n s)$ and $(0.505 \mathrm{~m}, 419$ tons and 2421 m.tons) for the full interaction system of loose side soil and the noninteraction system of fixed ground base, respectively. Indeed, the high result values indicate the high effect of the applied earthquake records. However figure 4 and other figures show shear force and bending moment values in building of fixed ground base ranging from (1.23 to 1.30) times that developed in buildings of $1,2,3$ and 5 basements with loose side soil.

\subsubsection{Effect of number of basements with dry side soil in loose state}

In general, the seismic shear force and bending moment of shear wall at ground level decreases as the number of basements increases. These values are $7 \%$ less in building of 5-basements compared to the building of 1-basement as shown in figure 5. This behavior is attributed to the increase of basement rigidity as the height of its retaining walls that founded on bed rock decreases; and hence absorbing more seismic forces. However, figure 5 shows maximum absolute values of (roof drift, shear force, and bending moment) at ground level of $(0.492 \mathrm{~m}, 339$ tons and $1962 \mathrm{~m} . t o n s)$ and $(0.491 \mathrm{~m}, 319$ tons and $1811 \mathrm{~m}$. tons $)$ for buildings of 1 - and 5-basements, 
respectively. These values can be compared with the above mentioned values for the building of 3-basements, and other figures herein after.

\subsubsection{Effect of side soil states}

Generally, the seismic responses of shear wall at ground level in buildings of (3basements or less) have minor changes due to the surrounding side soil states either loose or very dense in dry condition. This may be explained as the retaining walls parallel to earthquake direction, and supported on bed rock at its base, have enough in-plane bending stiffness to perform most of the basement rigidity without need for participation of the perpendicular retaining walls of laterally supporting dry loose side soil. Actually, little more effect of the side soil is found for the building of 5basements with very dense side soil state; where $\mathrm{X}$-displacement values at ground level (figure 6a) are higher than the $\mathrm{X}$-displacements for the other structural models (figure 4a) which nearly coincide with the earthquake records.

The above result is assured in figure 6 for the effect of changing the side soil from loose to very dense state on buildings of 3- and 5- basements. This figure shows maximum absolute ground shear force value of the shear wall of $(329,331$ and 341 tons) and (319, 562 and 357 tons) for the buildings of 3- and 5-basements with (loose, very dense state, and absence of side soil), respectively. In one hand, this figure shows minor change in results for the building of 3-basements. On the other hand, the maximum absolute ground shear force in building of 5-basements with very dense side soil state is 1.76 and 1.34 times that in building of loose side soil state and fixed ground base, respectively.

\subsection{Seismic behavior of under-ground portion of shear wall in building of different number of basements and side soil states}

Similar seismic behavior is noticed for under-ground portion of shear wall in all studied cases of basement numbers and side soil states, regardless the result values. The highest time history values of shear force in the above- and under-ground portions of shear wall are always developed at the first basement level. In addition, minor shear force values are always developed at lower levels below the first basement as shown in figures 8,11 , and 13c.

Figures 7,13a, 8a, and 11a show the time history charts of shear force at first basement level for the buildings of 1-, 2-, 3- and 5-basements, respectively. These figures show maximum absolute shear force values of (1.57, 1.64 and 1.54), (1.21, 1.20 and 1.16), (1.22, 1.26 and 1.20) and (1.20, 1.42 and 1.23) times the ground shear force of non-interaction system of fixed ground base, for side soil of (loose, very dense state and absence of side soil), respectively. It should be noted that the highest seismic shear force value is absorbed at the first basement level in the building of 1basement with very dense side soil. This assures increasing the basement rigidity as 
the number of basements decreases; while founded on bed rock.

Figures 9, 10 and 12 show the highest time history values of bending moment are always developed at the foundation level, for the buildings of 1-, 3-, and 5-basements, respectively. These figures show maximum absolute bending moment values of $(0.24,0.27$ and 0.21$),(0.24,0.32$ and 0.1$)$, and $(0.1,0.32$ and 0.07$)$ times that developed at ground level in building of fixed ground base, for (loose, very dense side soil state and absence of side soil), respectively. On the other hand, very low seismic bending moments are developed at other basement floors due to their low relative displacements.

Once more the above results show more effect of the very dense side soil on the seismic responses of under-ground portion of shear wall in building of 5-basements.

\subsection{Assessment of seismic responses of shear wall in building of basement(s) without accounting for side soil modeling (partial interaction)}

In fact, the three-dimensional interaction dynamic analysis is complex problem consuming a lot of computer needed capacity and run time. So, it is proposed to analyze the super-structure-basement system without accounting for modeling the side soil as partial interaction simulation to be assessed. Actually, differences up to $10 \%$ are found for the maximum absolute shear force value at $1^{\text {st }}$ basement level when applying this proposal to all studied models except the building of 5-basements with very dense side soil state.

The example results of figure 13 show the effect of ignoring the modeling of side soil on the shear forces of above- and under-ground portions of the shear wall in building of 2-basements with (loose, very dense state and absence of side soil). This figure shows maximum absolute shear force values of (332, 342 and 333 tons), (508, 505 and 485 tons) and $\left(213,215\right.$ and 66 near foundation) at ground, $1^{\text {st }}$ and $2^{\text {nd }}$ basement levels, respectively. It should be noted that, figure 13 also shows an increase in the maximum absolute value of shear force at $1^{\text {st }}$ basement level by $(53 \%, 47 \%$ and $45 \%)$ compared with that at ground level for (loose, very dense state and absence of side soil), respectively.

\section{Summary and Conclusions:}

Basements often form relatively stiff structural boxes containing diaphragms and walls surrounded by soil. Since the building is seismically excited by the motion of the basement, it is appropriate to assess the likely motion on full interaction analysis of super-structure with basements and dry side soil. The in hand dynamic time history study investigates the seismic performance of shear wall as a part of threedimensional building of 10 above-ground stories and different number of basements 
and density states of side soil, considering the system resting on bed rock. In addition, the building with traditional fixed supports at ground level is analyzed for assessing as a non-interaction system that commonly used in design practice. Further, a proposed simplified model for the building of basement(s) without accounting for the side soil modeling is assessed as a partial interaction simulation to reduce the problem complexity and the computer capacity and run-time needed by the dynamic analysis of full interaction system. However, the following conclusions are summarized based on the results of the studied buildings; keeping in mind that different structural configuration and earthquake records may lead to different dynamic properties and hence different results:

1- The maximum absolute values of ground shear force and bending moment developed in shear-wall in building of fixed ground supports are 1.27 times the average corresponding values of full interaction systems of 1-, 2-, 3- and 5basements considering dry side soil in loose state. The roof drift is found with increase of around $2 \%$ as well.

2- Buildings of different number of basements with dry side soil in loose state develop nearly close values of ground seismic shear force and bending moment of the shear wall. These seismic responses are increased, as maximum limit, by $7 \%$ for the building of 1-basement compared to that of 5-basements, while negligible difference is found for the roof drift.

3- The change of dry side soil from loose to very dense state has minor effect on the maximum seismic responses of the above- and under-ground portions of the shear wall in buildings of (3-basements or less). On the other hand, higher effect is found in building of 5-basements.

4- The highest absolute value of seismic shear force in the whole shear wall is always developed at the $1^{\text {st }}$ basement floor level, which matching with the previous studies. This value is found to be: $(1.57,1.64$ and 1.54), $(1.21,1.20$ and $1.16),(1.22,1.26$ and 1.20) and $(1.20,1.42$ and 1.23) times the base shear force in building with fixed ground base for (loose, very dense state and absence of side soil) in buildings of 1-, 2-, 3- and 5-basements, respectively. On the other hand, minimal seismic shear force values are developed at basements of lower levels.

5- The maximum seismic bending moment in under-ground portion of the shear wall is developed at raft foundation levels for buildings of different number of basements and side soil states. The highest bending moment value of all studied building cases is found to be 0.32 times the bending moment at ground level of the building of ground fixed base.

6- The seismic inertial forces are mainly resisted by the basement retaining walls that are parallel to the earthquake direction, due to its large in-plane stiffness, other than the perpendicular ones of lateral supporting loose dry side soil. This is confirmed by the maximum difference of $10 \%$ found between the maximum absolute values of design parameters of all studied building systems, except the 
building of 5-basements and with dry side soil in very dense state.

6. Recommendation: Further studies should be carried out to investigate the effect of type and thickness of foundation-soil under basement instead of bed rock.

\section{References:}

[1] T. H. Lee and K. M. Mosalam, Seismic Demand Sensitivity of Reinforced Concrete Shear-wall Building using FOSM Method, Earthquake Engineering and Structural Dynamics, Wiley Inter Science (www.interscience.wiley.com), DOI: 10.1002/eqe.506, 34, 1719-1736, 1 June 2005.

[2] J. H. Wood, Earthquake Design of Rectangular Underground Structures, Paper number 39, Proceedings of New Zealand Society for Earthquake Engineering conference (NZSEE), 2005.

[3] A. Gouasmia and K. Djeghaba, Non-linear Seismic Soil-structure Interaction Analysis of Structures Based on the Substructure Method, Asian Journal of Civil Engineering (Building and Housing), Vol. 8, No. 2, 183-201, 2007.

[4] R. E. Melchers and R. Hough, Modeling Complex Engineering Structures, published book by American Society of Civil Engineering, Reston, Virginia, USA 2007.

[5] Council on Tall Buildings and Urban Habitat (CTBUH), Recommendations for the seismic design of high-rise buildings, A Consensus Document of CTBUH Seismic Working Group, Illinois Institute of Technology, Chicago, USA, 2008.

[6] H. El Ganainy and M. H. El Naggar, Seismic Performance of three-dimensional frame structures with underground stories, Soil Dynamics and Earthquake Engineering, Vol. 29, Issue 9, 1249-1261, Sept. 2009.

[7] D. G. Lee and H. S. Kim, Efficient Seismic Analysis of High-rise Buildings Considering the Basements, Paper No. 4.11.01 of NZSEE 2001 Conference.

[8] E. Giuriani and A. Gubana, Underground Box Structure as a Foundation for Shear Walls in Seismic Resistant Buildings, Journal of Structural Engineering, ASCE, Vol. 133 No. 4, 559-566, April 2007.

[9] P. Riva, A. Meda, and E. Giuriani, Cyclic Behavior of a Full Scale RC Structural Wall, Journal of Engineering Structure, Vol. 25, No. 6, 835-845, 2003.

[10] K. V. Subramanian, R. D. Chandrasekaran and G. Vishalakshi, Modeling of Shear Walls, Transaction of the $15^{\text {th }}$ International Conference on Structural Mechanics in Reactor Technology (SMiRT-15), Seoul, Korea, August 15-20, 1999.

[11] M. Browne, A. Carr and D. Bull, The Analysis of Reinforced Concrete Rocking Wall Behavior, Paper number 15, Proceedings of New Zealand Society for Earthquake Engineering Conference (NZSEE), 2006.

[12] C. S. Desai and H. M. Galagoda, Earthquake analysis with generalized plasticity model for saturated soil, Earthquake Engineering and Structural Dynamics, Vol. 18, 903-919, March 1989.

[13] ADINA Program Version 8.2, (Automatic Dynamic Incremental Nonlinear Analysis), The Finite Element System for Structures, Heat Transfer, and CFD, ADINA R\&D INC., Watertown USA, 2004. 
[14] M. I. Todorovska, Full-scale experimental studies of soil-structure interaction, ISET Journal of Earthquake Technology, paper number 422, Vol. 39, 139-165, India, Sept. 2002.

[15] G. M. Kandge, Influence of mode dependent Rayleigh damping on transient stress response, Master Degree Thesis, Department of Mechanical Engineering, Bleking Institute of Technology, Karlskrona, Sweden, 2007. 


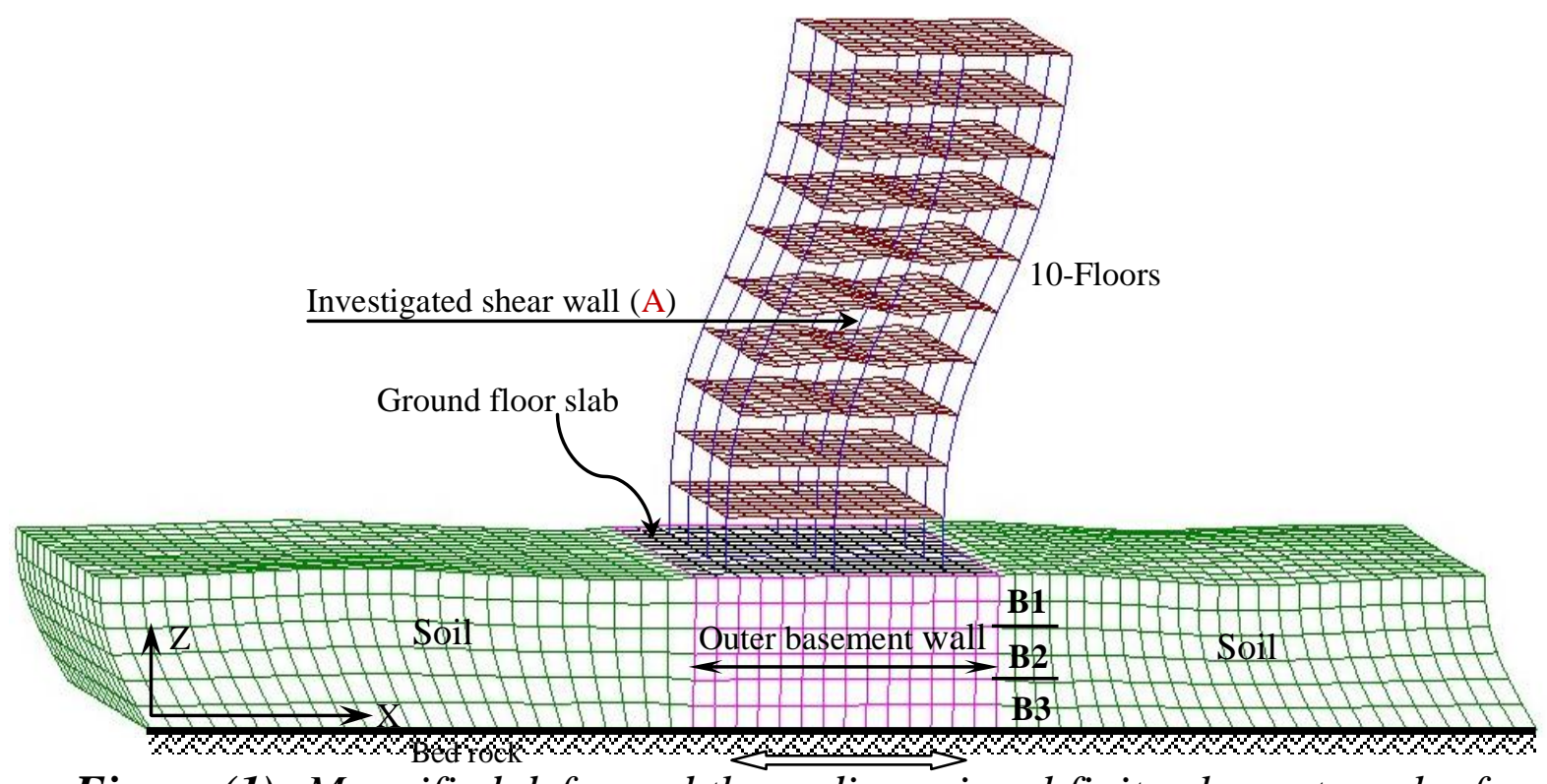

Figure (1): Magnified deformed three-dimensional finite element mesh of super-structure with 3-basements and side soil (by ADINA, at $t=8.48 \mathrm{sec}$.)

(Outside view)

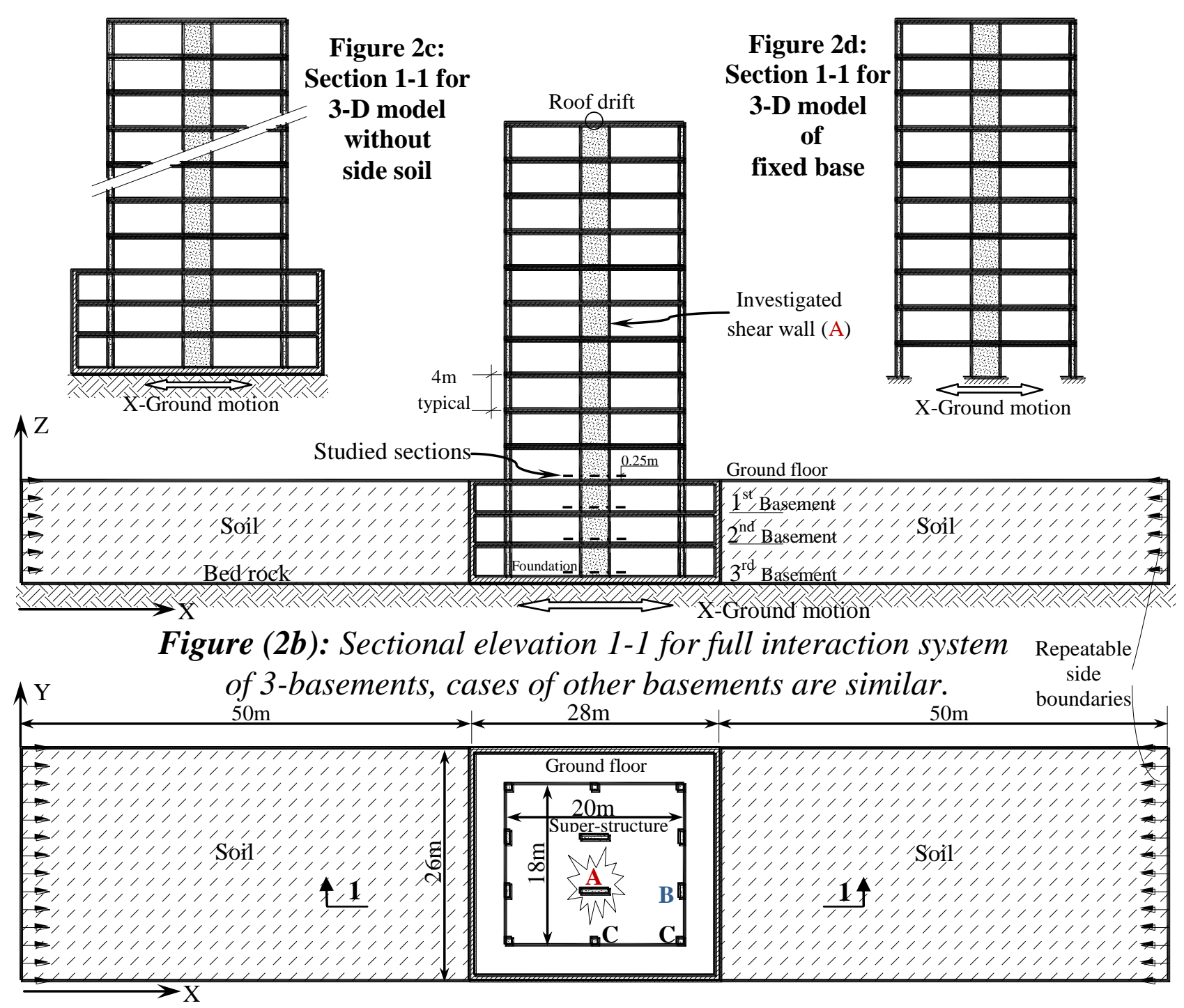

Figure (2a): Schematic plan of super-structure with basements and side soil. 


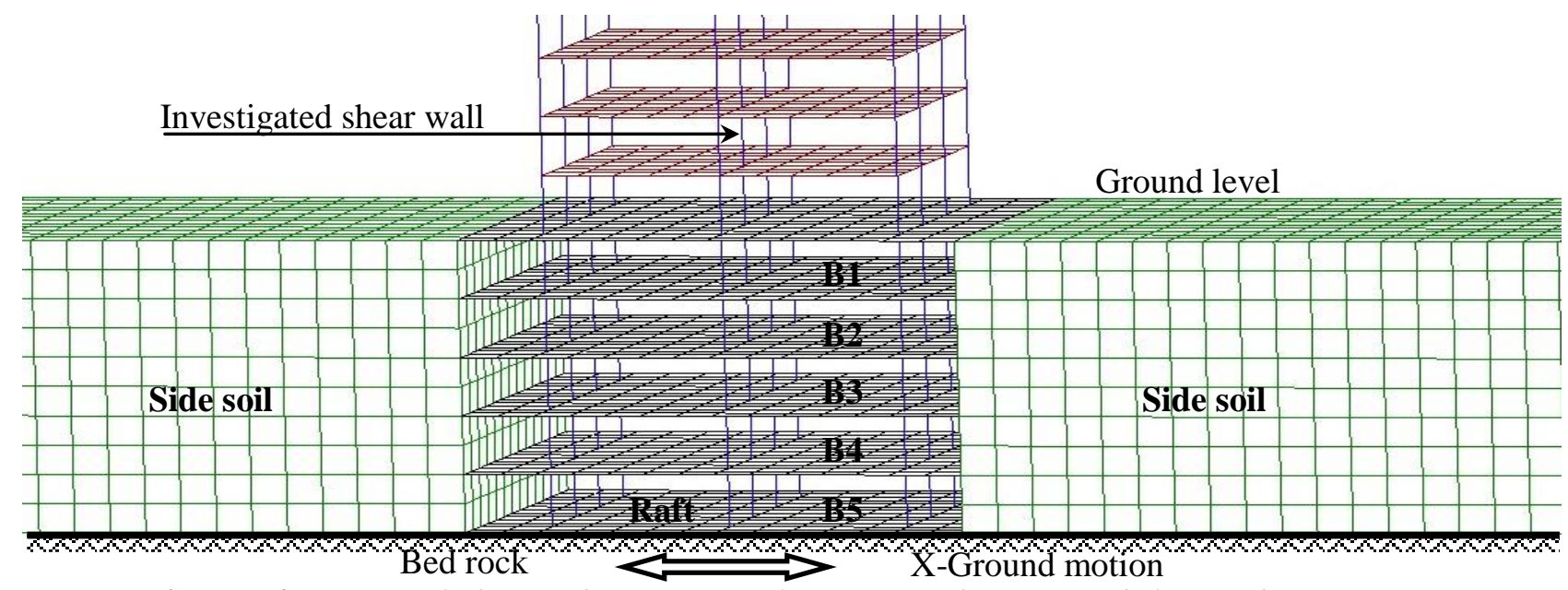

Figure 3: Partial three-dimensional F.E. mesh for model of 5-basements.

[The basement walls are hidden for clarity, (by ADINA)].

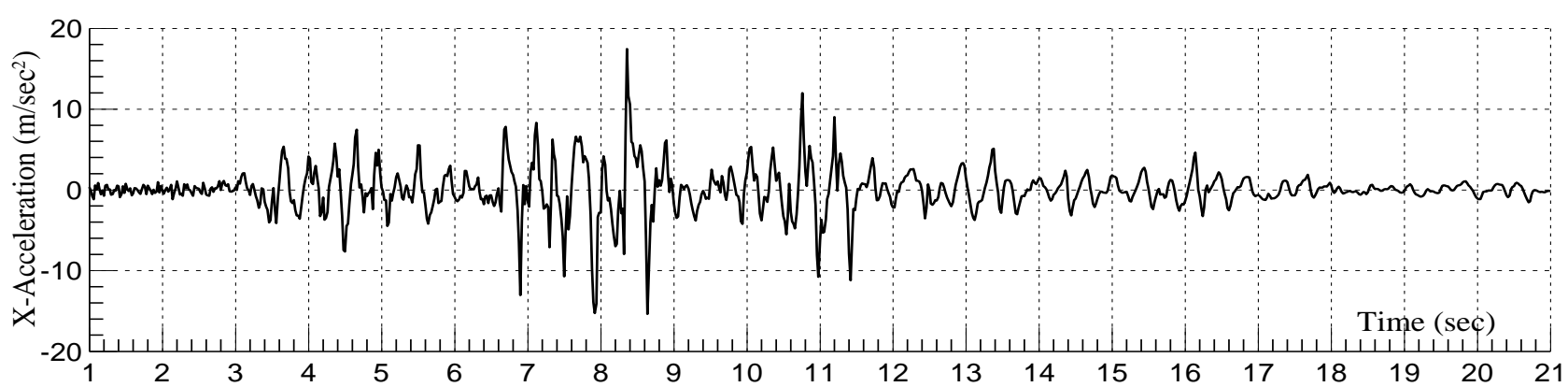

Figure 3a: Acceleration-time records of Northridge 1994 earthquake

Table 1: Studied 3-D models and variables

\begin{tabular}{|c|c|c|c|c|c|c|c|c|}
\hline \multicolumn{9}{|c|}{ Full interaction models } \\
\hline \multirow{2}{*}{$\begin{array}{c}\text { Objective } \\
\text { No. }\end{array}$} & \multirow{2}{*}{$\begin{array}{c}\text { Model } \\
\text { No. }\end{array}$} & \multirow{2}{*}{$\begin{array}{c}\text { Super- } \\
\text { structure }\end{array}$} & \multicolumn{4}{|c|}{ Number of basements } & \multicolumn{2}{|c|}{ Side soil state } \\
\hline & & & 1 & 2 & 3 & 5 & Loose & Very dense \\
\hline \multirow{8}{*}{$\mathrm{A}, \mathrm{B}, \mathrm{C}$} & M1 & \multirow{8}{*}{$\begin{array}{c}\text { 10-floors } \\
\text { of } \\
\text { flat slabs } \\
\text { on } \\
\text { shear-walls } \\
\text { and columns }\end{array}$} & * & & & & * & \\
\hline & M2 & & & $*$ & & & $*$ & \\
\hline & M3 & & & & $*$ & & * & \\
\hline & M4 & & & & & $*$ & $*$ & \\
\hline & M5 & & $*$ & & & & & * \\
\hline & M6 & & & $*$ & & & & * \\
\hline & M7 & & & & $*$ & & & $*$ \\
\hline & M8 & & & & & $*$ & & $*$ \\
\hline \multicolumn{9}{|c|}{ Traditional fixed base model (non interaction) } \\
\hline A & M9 & Same as above & \multicolumn{6}{|c|}{ Fixed base at ground floor level } \\
\hline \multicolumn{9}{|c|}{ Partial interaction models (without side soil) } \\
\hline \multirow{4}{*}{$\mathrm{C}$} & M10 & \multirow{4}{*}{ Same as above } & * & & & & \multirow{4}{*}{\multicolumn{2}{|c|}{ Without side soil }} \\
\hline & M11 & & & $*$ & & & & \\
\hline & M12 & & & & $*$ & & & \\
\hline & M13 & & & & & $*$ & & \\
\hline
\end{tabular}




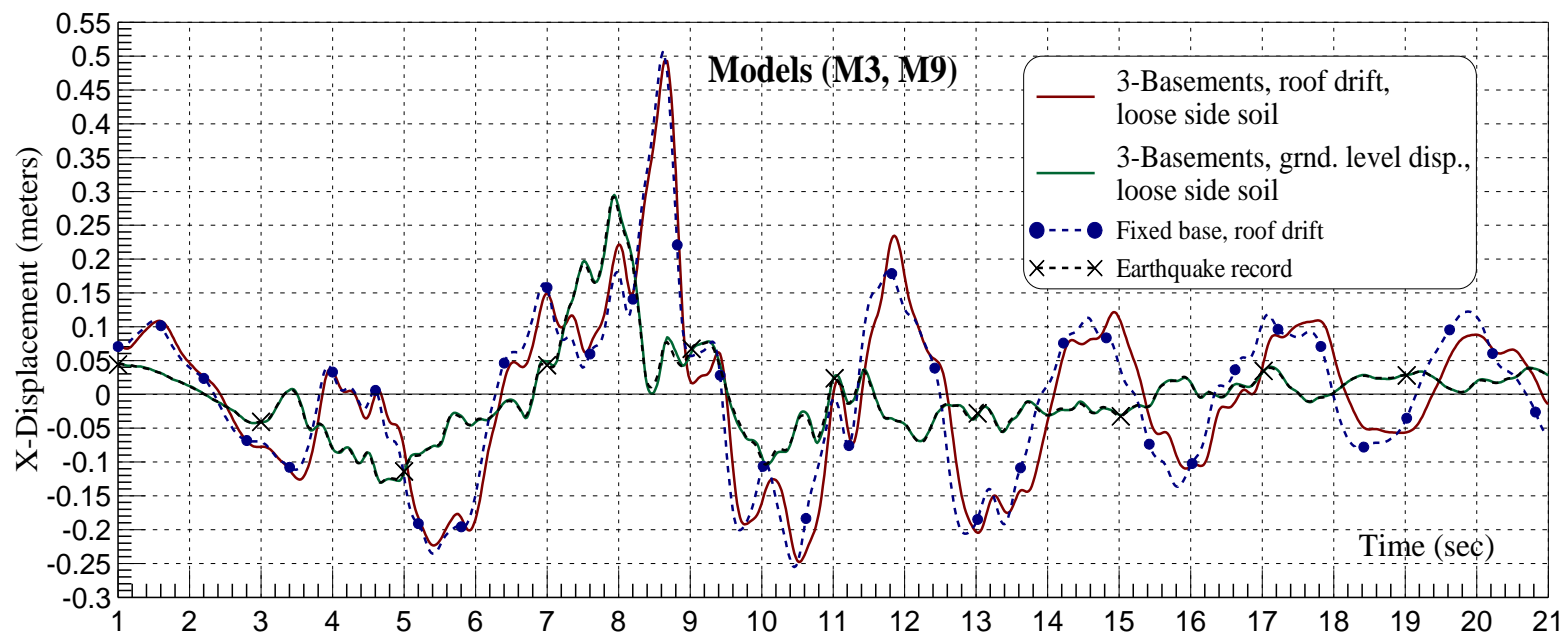

a): Displacements in earthquake direction

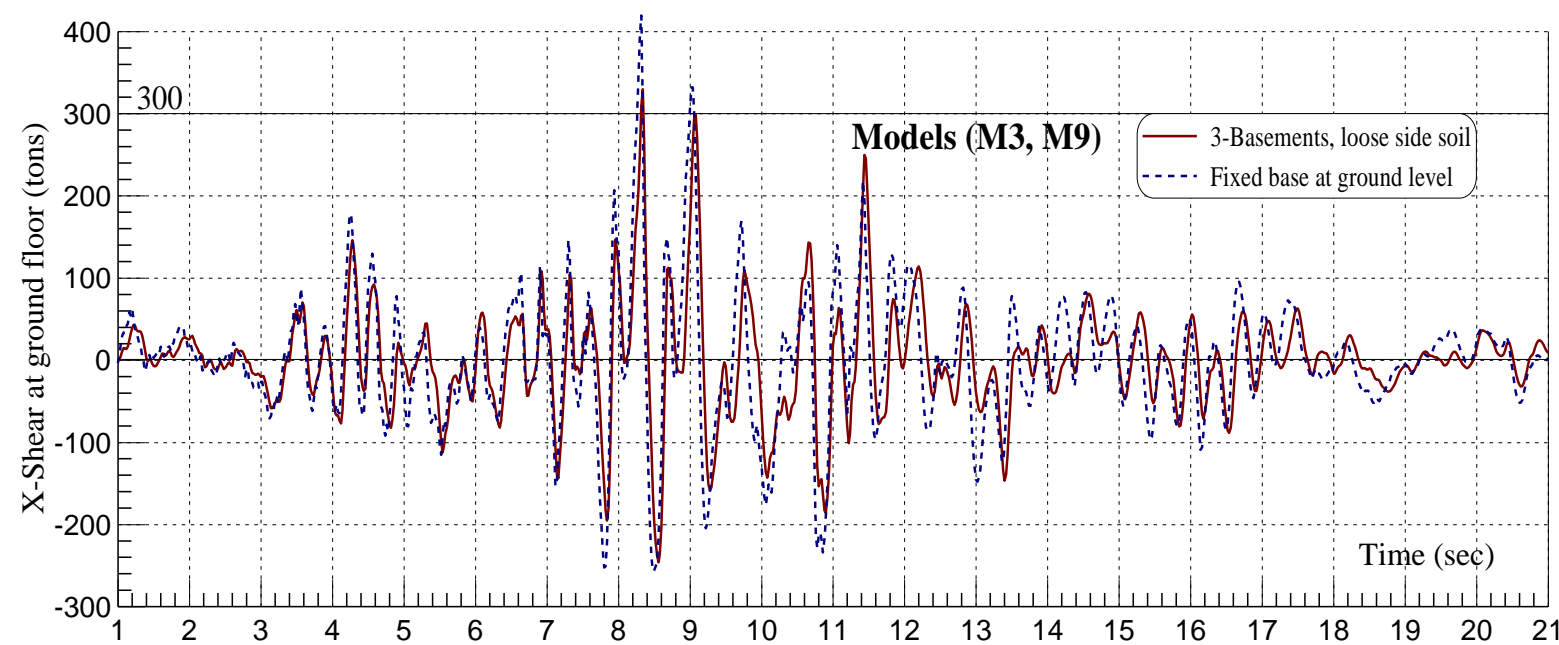

b): Shear force at ground level

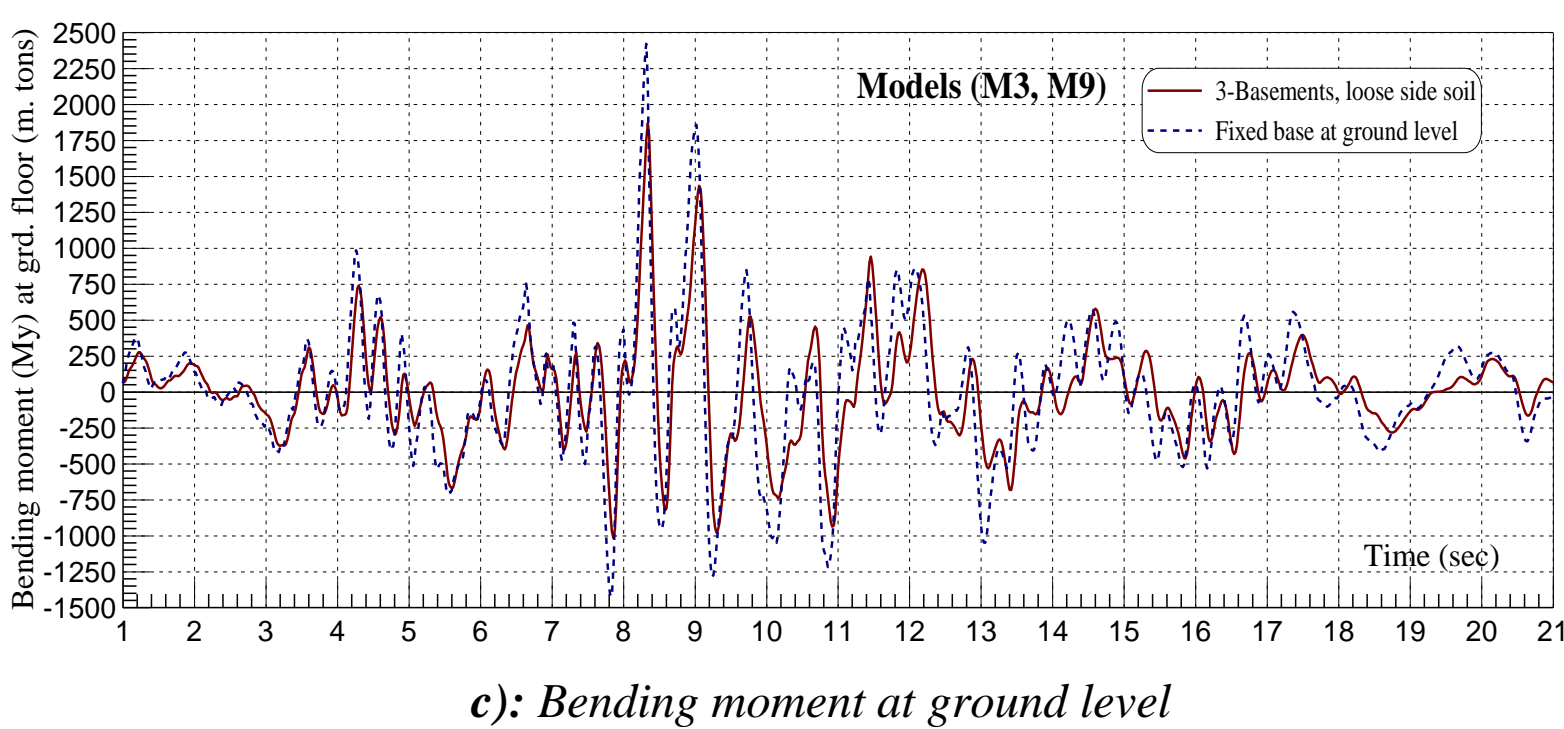

Figure (4): Comparison of above-ground seismic responses of shear-wall in building of: fixed ground base, and 3-basements surrounded by loose dry soil. 

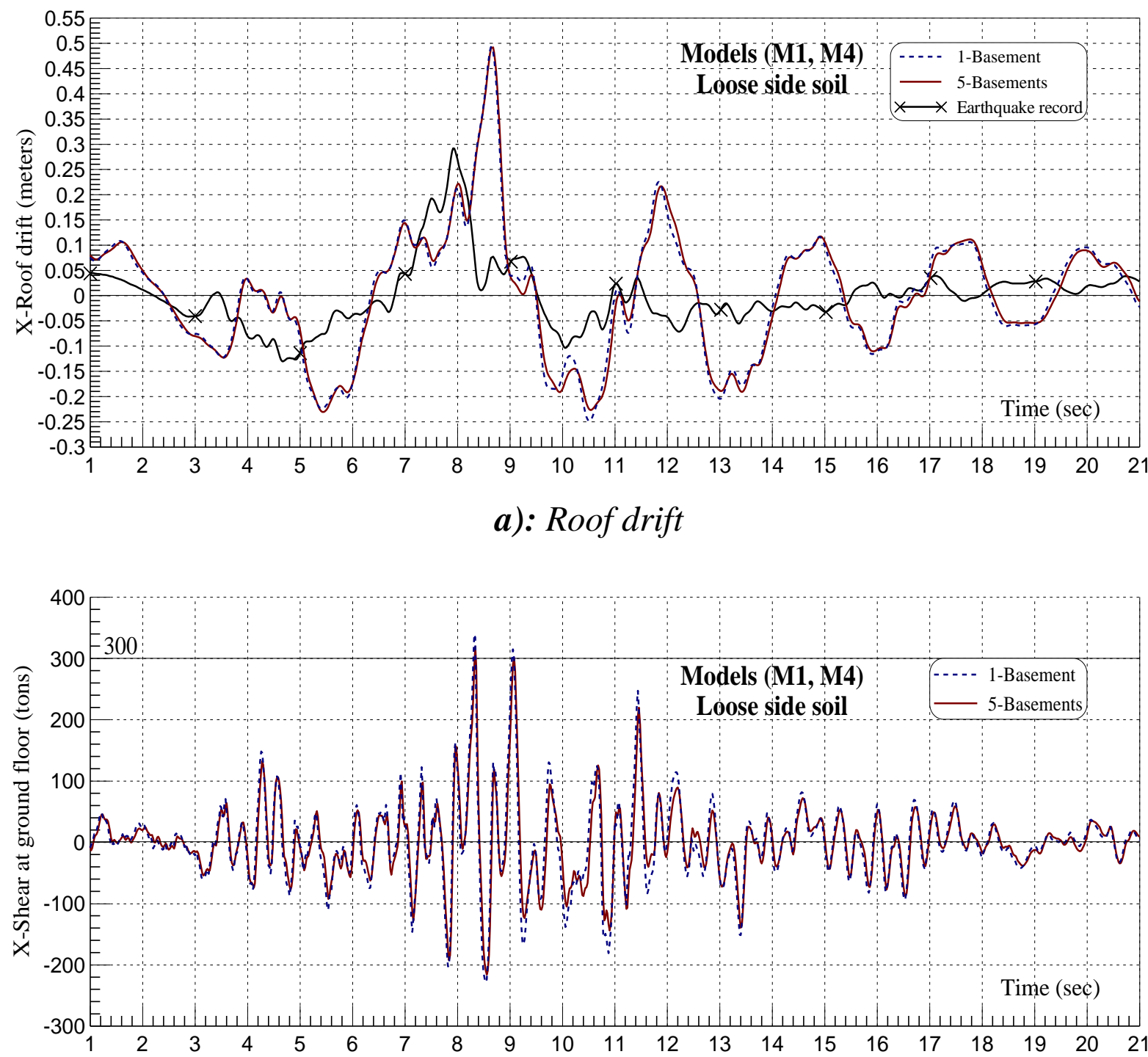

b): Shear force at ground level

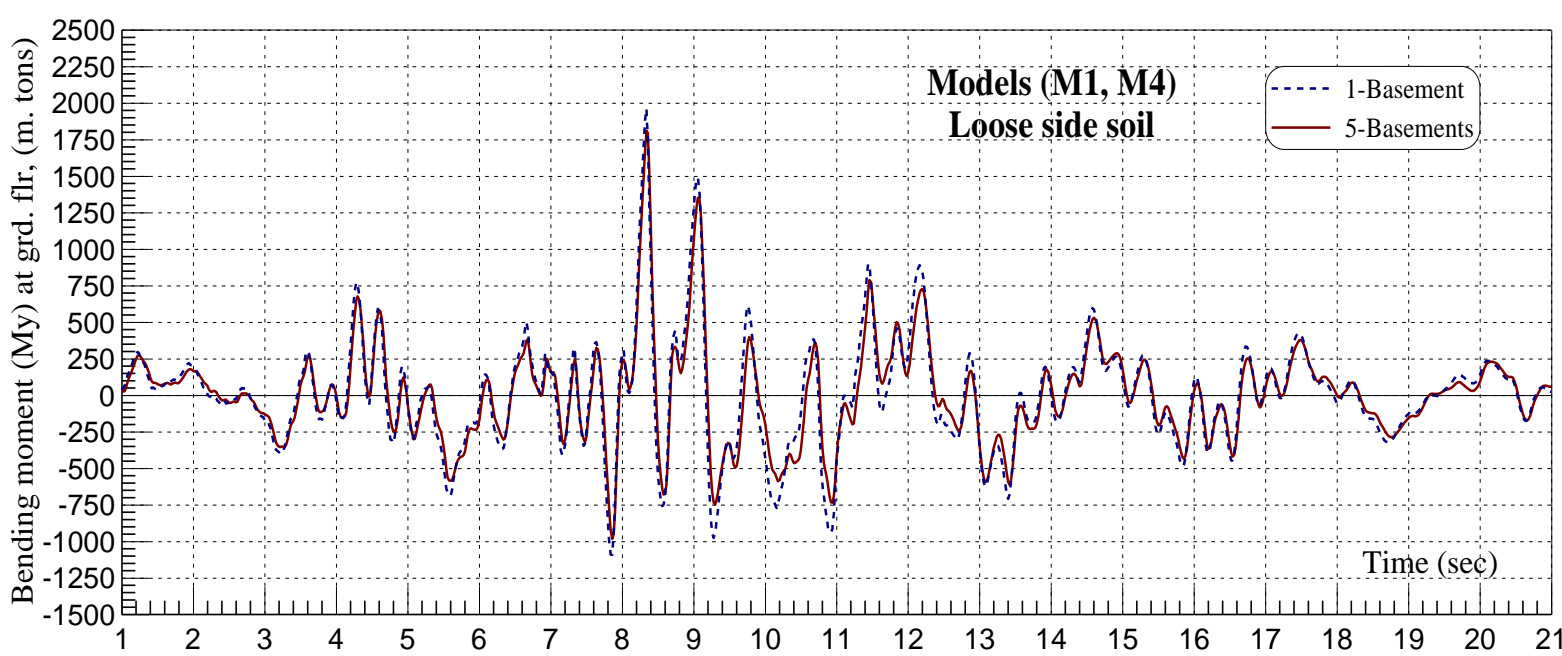

c): Bending moment at ground level

Figure (5): Seismic responses of above-ground portion of shear-wall in building of 1 - and 5-basements with loose dry side soil, (effect of number of basements). 


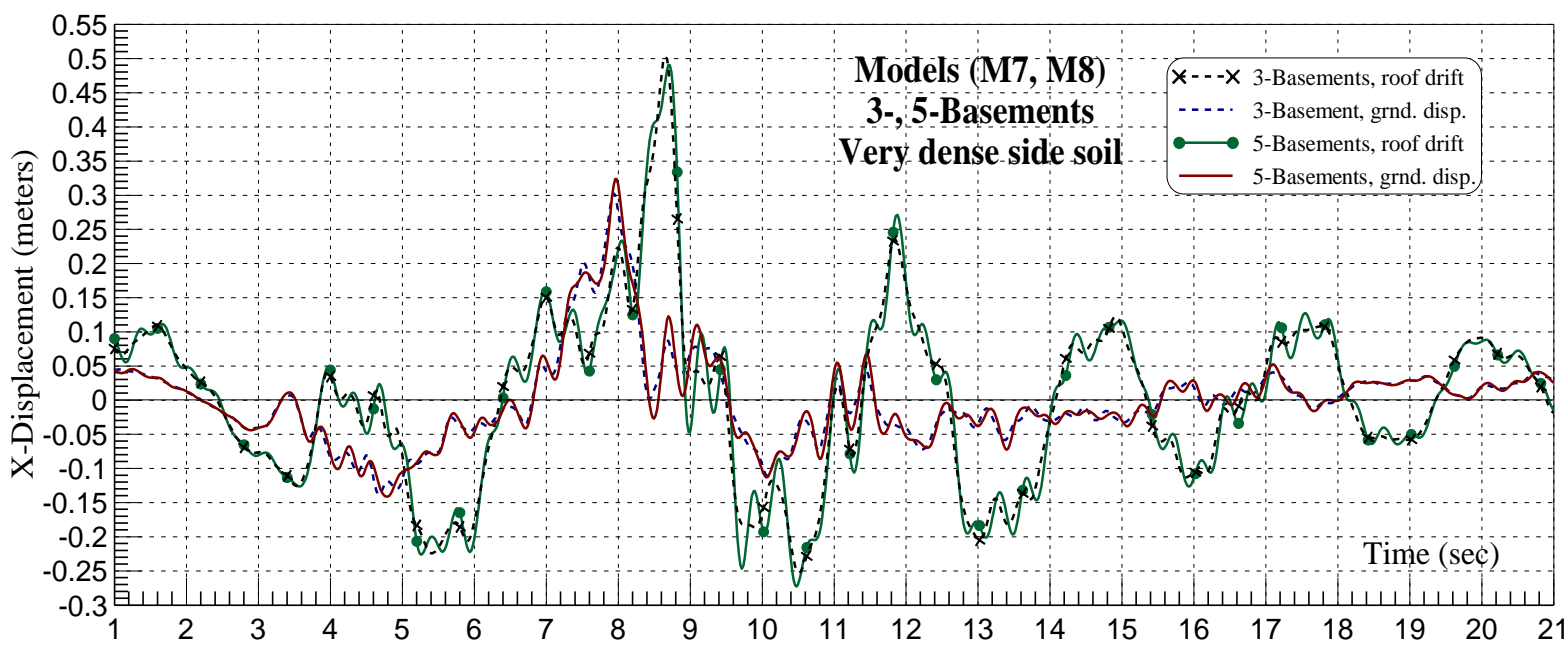

a): X-displacements for interaction svstems of 3- and 5-basements

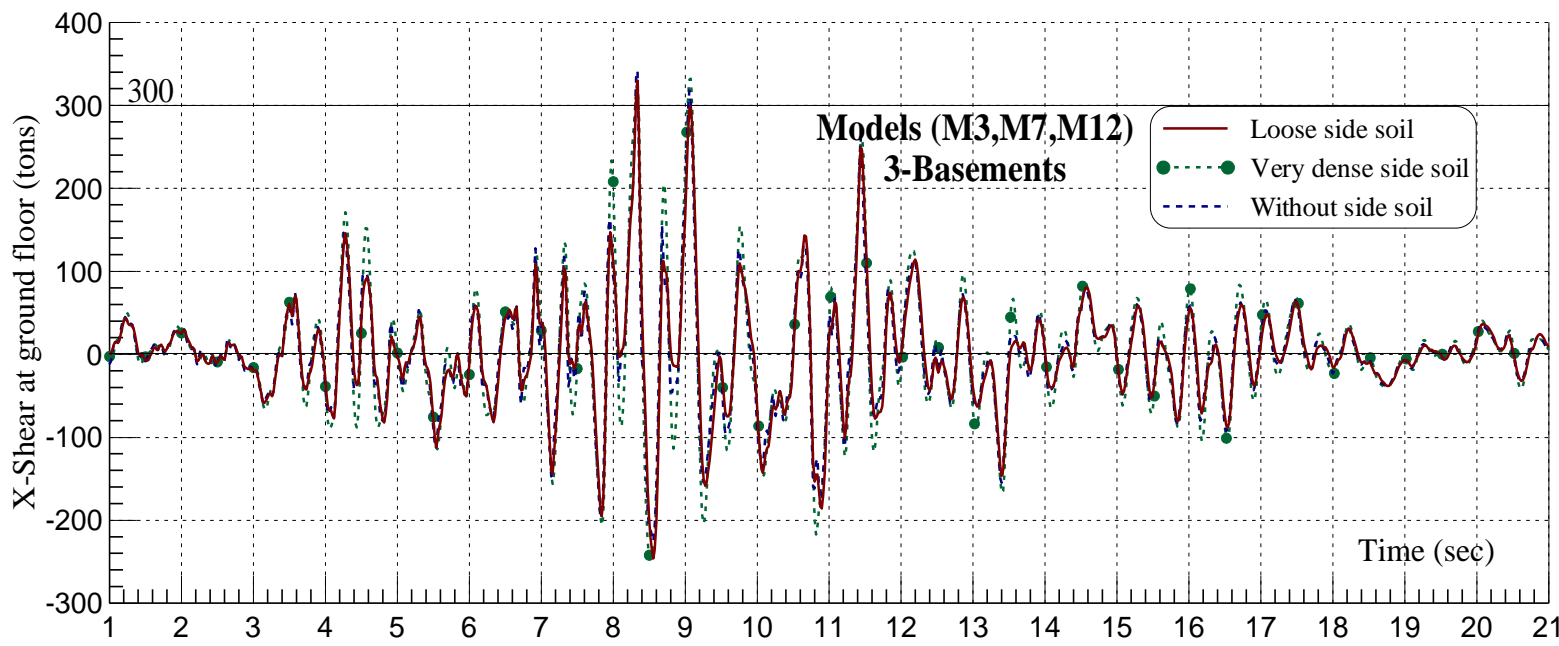

b): Shear force at ground floor for interaction system of 3-basements

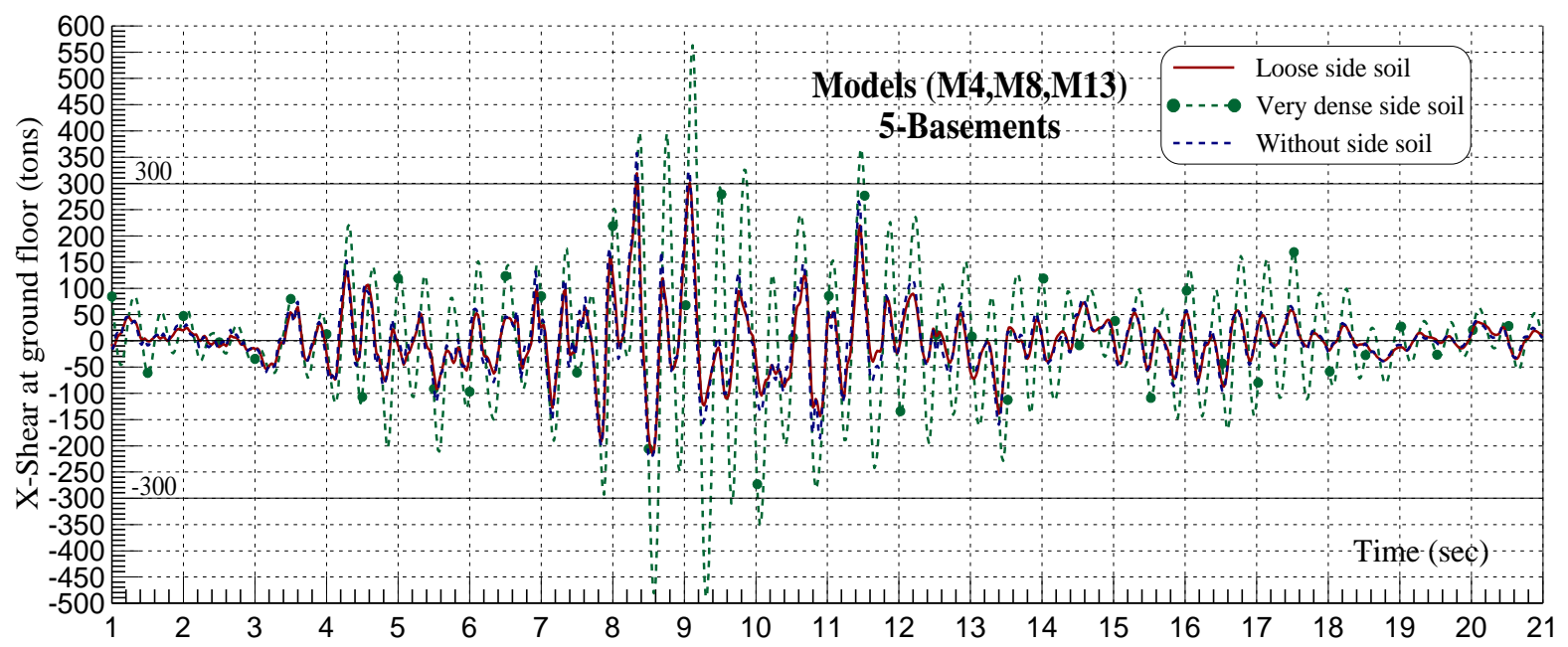

c): Shear force at ground floor for interaction system of 5-basements

Figure (6): Effect of side soil states on seismic responses of above-ground portion of shear wall in super structure with 3-and 5-basements. 


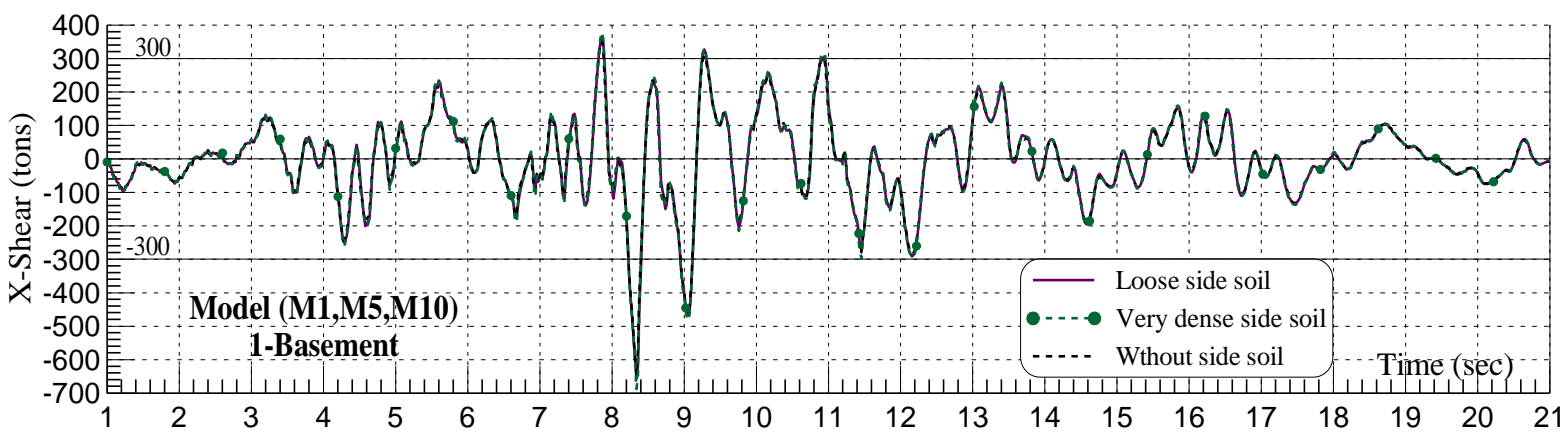

Figure (7): Seismic shear force in basement portion of shear wall in building of 1-basement without and with two states of dry side soil.

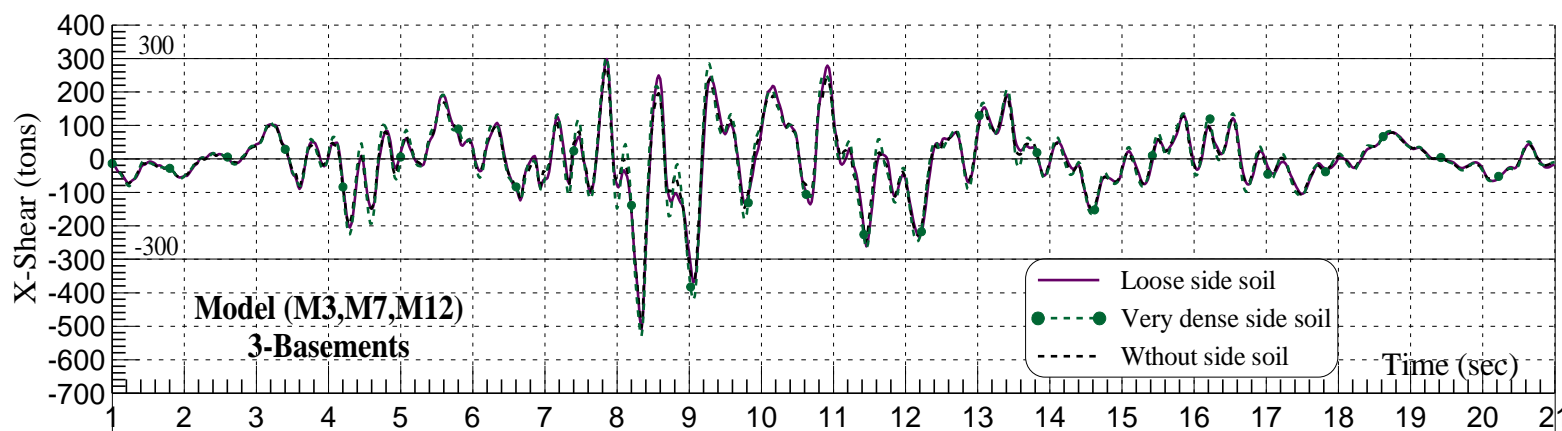

a): Shear force at $1^{\text {st }}$ basement floor level

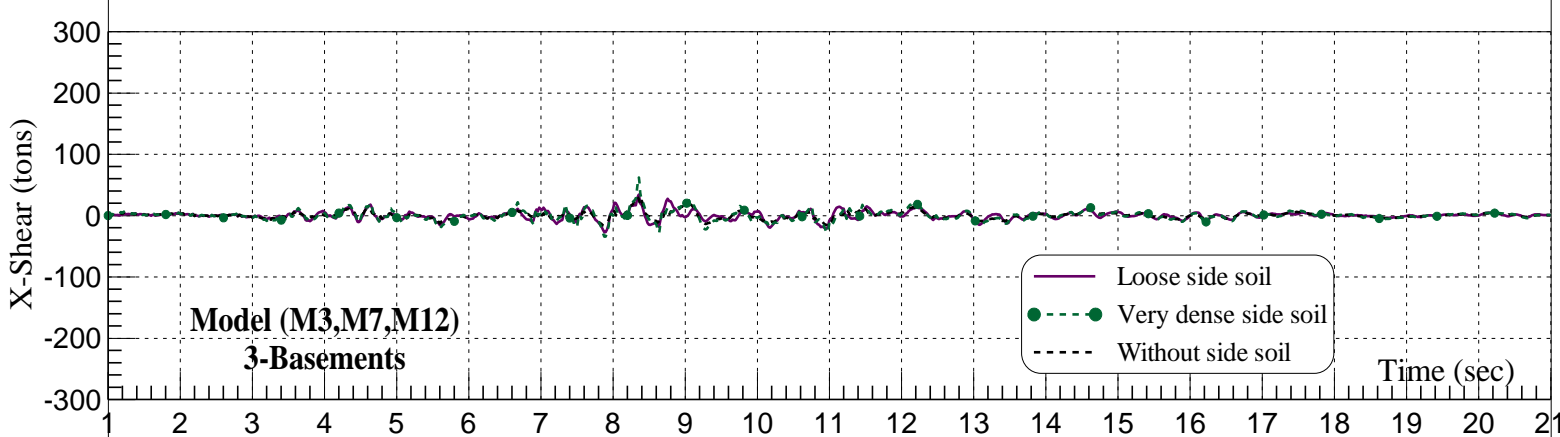

b): Shear force at $2^{\text {nd }}$ basement floor level

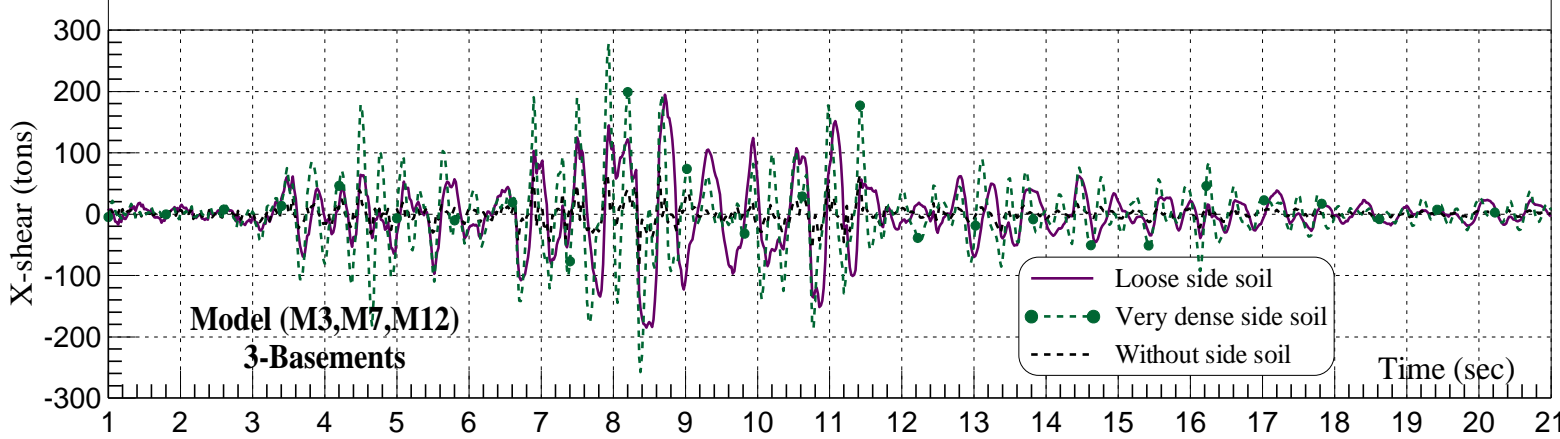

c): Shear force at $3^{\text {rd }}$ basement floor level

Figure (8): Seismic shear force in basement portion of shear wall in building of 3-basements without and with two states of dry side soil. 


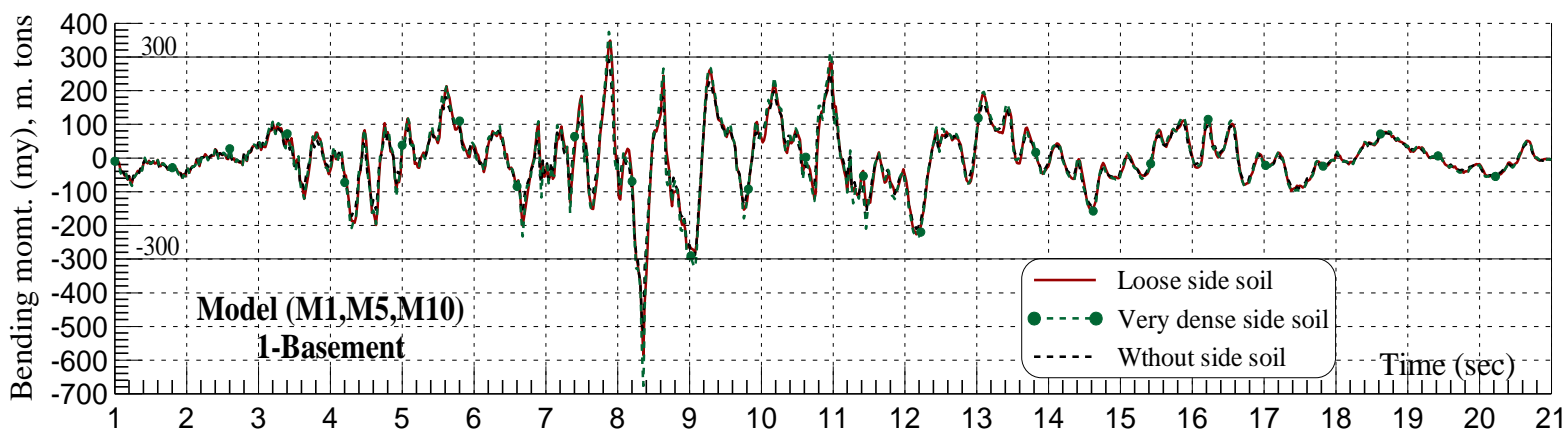

Figure (9): Seismic bending moment in basement portion of shear wall in building of 1-basement without and with two states of dry side soil.

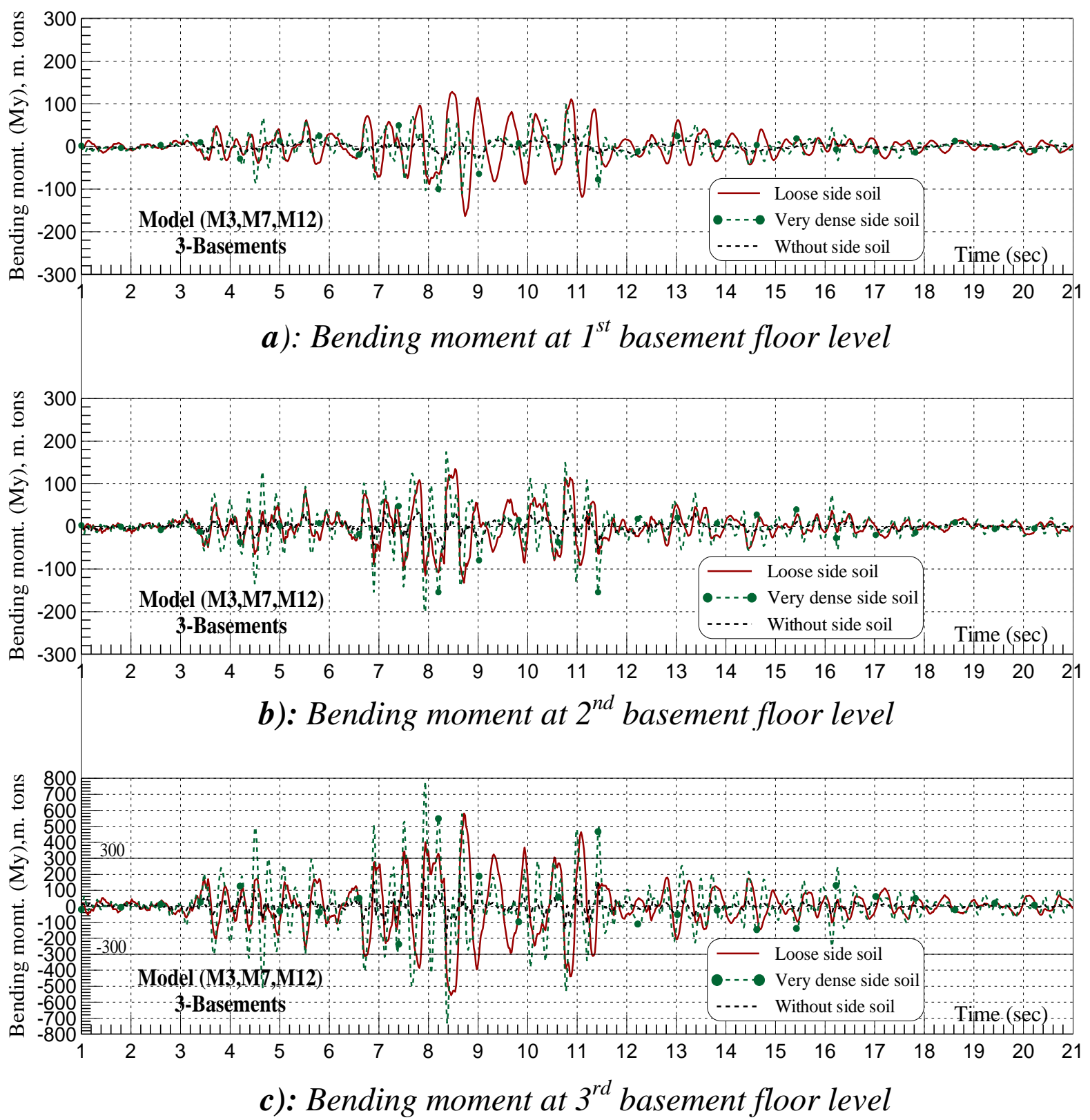

Figure (10): Seismic bending moment in basement portion of shear wall in building of 3-basements without and with two states of dry side soil. 

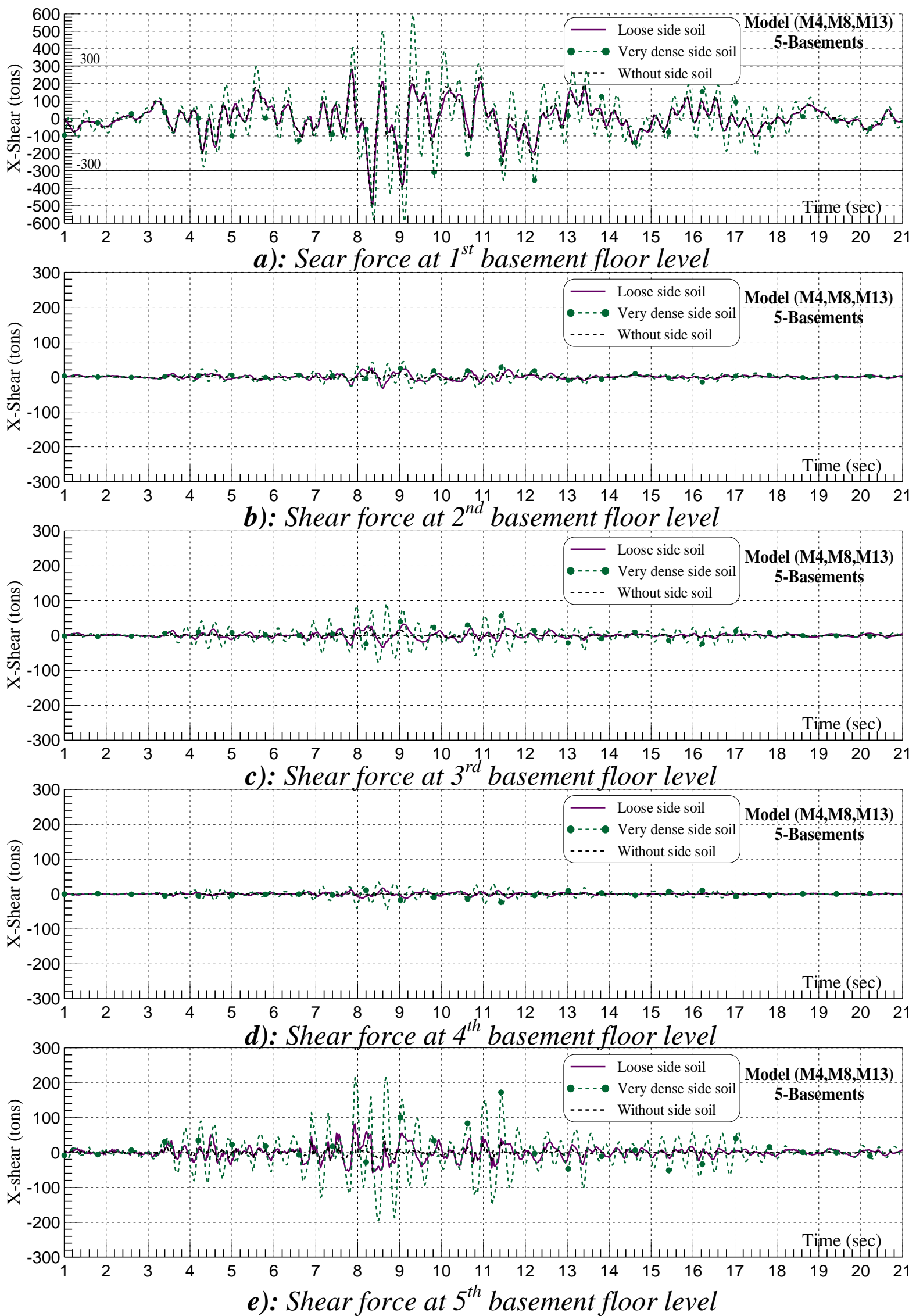

Figure (11): Seismic shear force in basement portion of shear wall in building of 5-basements without and with two states of dry side soil. 

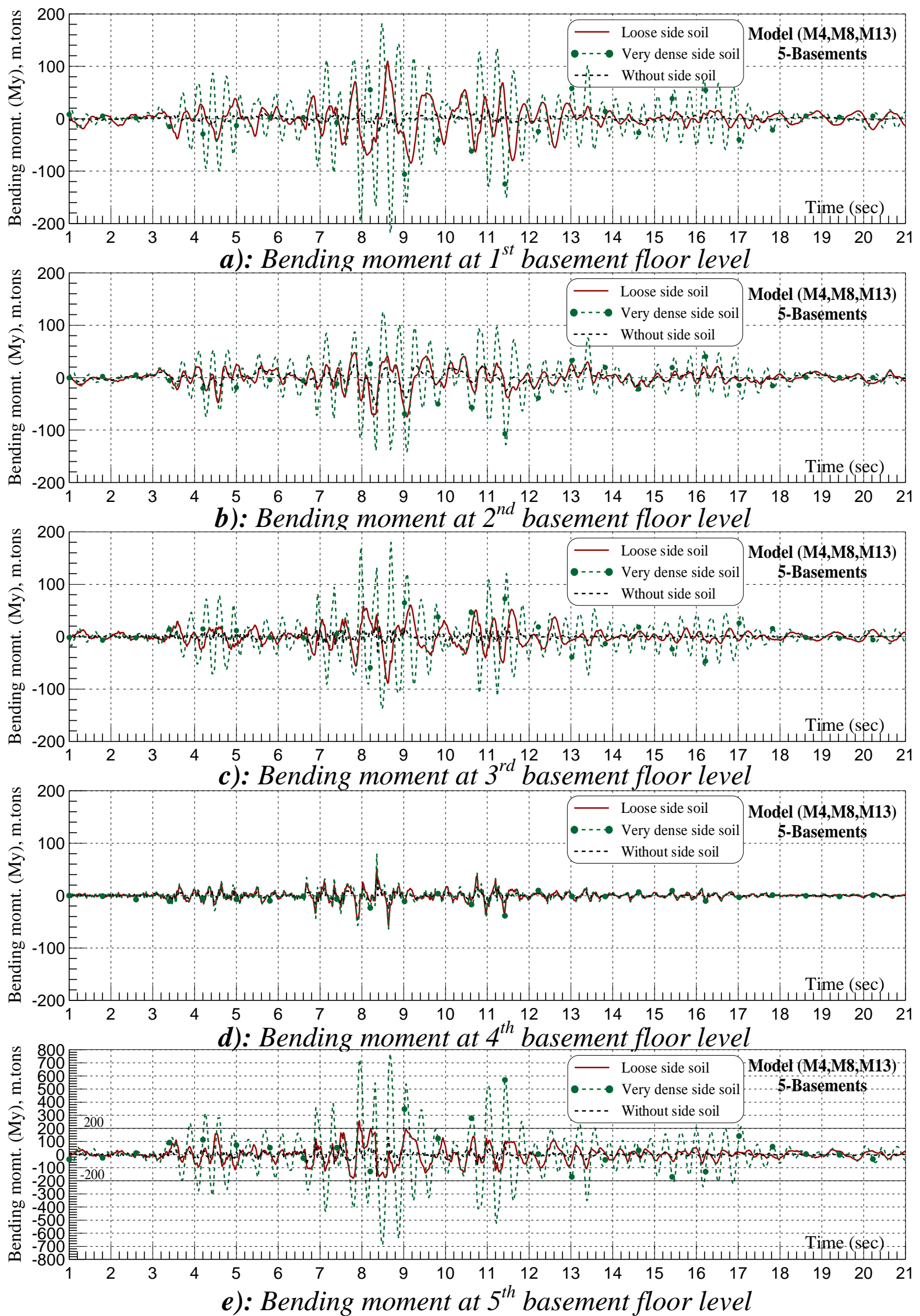

Figure (12): Seismic bending moment in basement portion of shear wall in building of 5-basements without and with two states of dry side soil. 

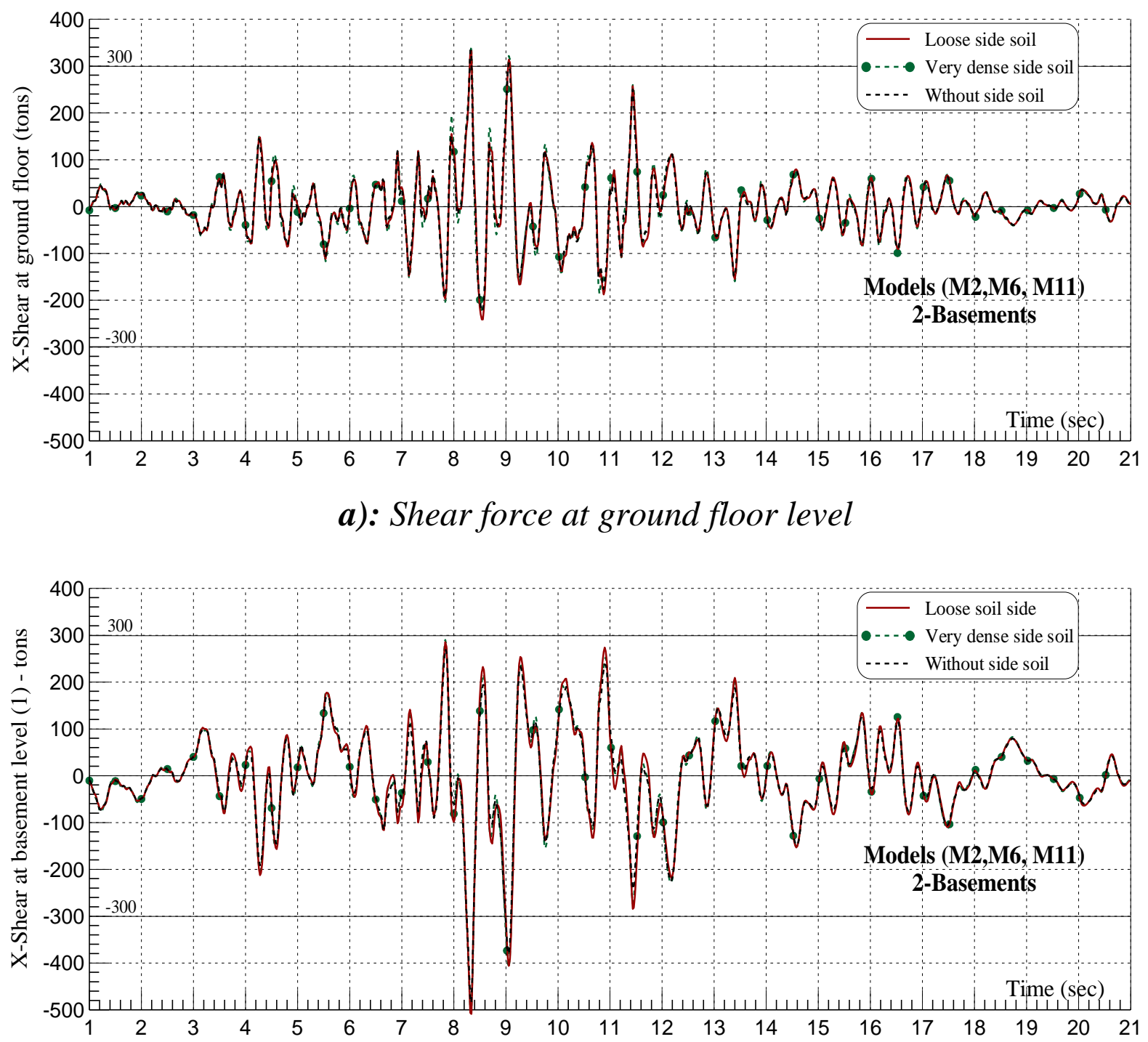

b): Shear force at $1^{\text {st }}$ basement floor level

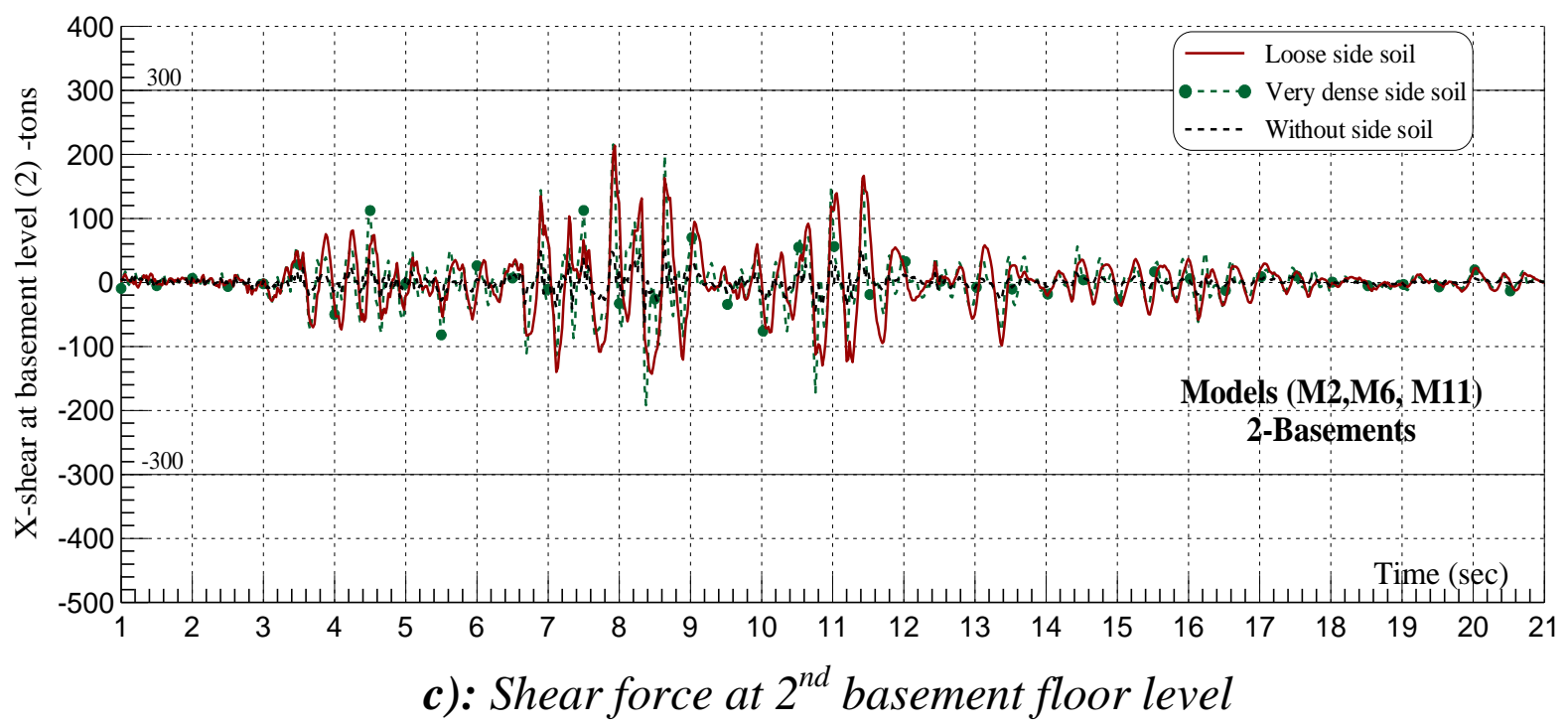

Figure (13): Seismic responses of shear-wall in building of 2-basements with and without accounting for the side soil modeling. 